\title{
Influence of Ramadan Fasting on Hemoglobin A1C, Lipid Profile, and Body Mass Index among Type 2 Diabetic Patients in Najran City, Saudi Arabia
}

\author{
Hatem Mohamed ${ }^{1 *}$, Anass M. Abbas ${ }^{2}$, Mohammed Ayed Huneif ${ }^{3}$, Seham M. Alqahtani ${ }^{3}$, Awad Mohamed Ahmed ${ }^{4}$, \\ Asaad M. A. Babker ${ }^{5}$, Ehab A. M. Elagab ${ }^{6}$, Parvez I. Haris ${ }^{7}$ \\ ${ }^{1}$ Department of Family and Community Medicine, College of Medicine, Najran University, Najran, Saudi Arabia; ${ }^{2}$ Department \\ of Clinical Laboratory Sciences, Faculty of Applied Medical Sciences, Jouf University, Saudi Arabia; ${ }^{3}$ Department of Pediatric, \\ College of Medicine, Najran University, Saudi Arabia; ${ }^{4}$ Department of Internal Medicine, College of Medicine, Najran University, \\ Najran, Saudi Arabia; ${ }^{5}$ Department of Medical Laboratory Sciences, College of Health Sciences, Gulf Medical University, \\ Ajman, United Arab Emirates; ${ }^{6}$ Department of Pathology, College of Medicine, Najran University, Najran, Saudi Arabia; ${ }^{7}$ Faculty \\ of Health and Life Science, De Montfort University, Leicester, UK
}

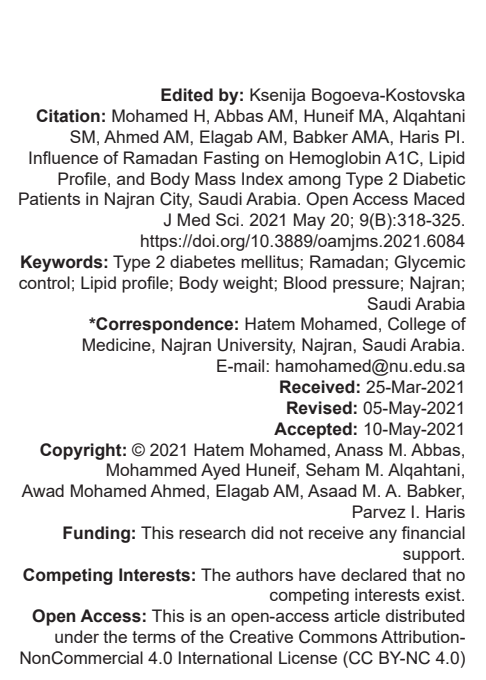

\section{Introduction}

In Islam, fasting during the month of Ramadan is one of the five pillars of faith [1]. Ramadan fasting is an obligatory and essential practice carried out by adult Muslims all over the world. Every adult Muslim is required to fast from dawn to sunset for a month during Ramadan in the Islamic (Hijri) calendar [2]. Fasting means abstinence from food, drink, sexual activities, and smoking from dawn to dusk [2]. The sick, the traveler, the fragile elderly, pregnant women, menstruating, and lactating ladies are exempted from fasting [2]. The number of Muslim patients with diabetes who choose to fast during Ramadan is increasing and this could create

\begin{abstract}
BACKGROUND: Saudi Arabia is known to have one of the highest prevalence of diabetes in the world. The impact of AIM: The current study was aimed at assessing the impa profile, blood pressure, and body mass index (BMI) in adult Saudis with Type 2 diabetes residing in Najran city. month of Ramadan and were attending the outpatient clinics of Nairan University Hospital. Fasting blood samples were taken 1 month before and 1 month after Ramadan to determine glycated hemoglobin and fasting lipid profile

RULTS: As many as $176(60.9 \%)$ of the participants reported to be physically inactive during Ramadan. There was a statistically significant $(\mathrm{p}<0.05)$ decrease in the mean percentage of HbA1c when comparing before Ramadan detected in the mean concentrations of LDL before $(3.39 \pm 1.06 \mathrm{mmol} / \mathrm{L})$ and after $(2.40 \pm 0.83 \mathrm{mmol} / \mathrm{L})$ Ramadan The mean concentration of TC (before $=5.98 \pm 2.00 \mathrm{mmol} / \mathrm{L}$; after $=4.05 \pm 1.18 \mathrm{mmol} / \mathrm{L}$ ) and TG (before $=2.97 \pm$ $1.78 \pm 0.74 \mathrm{mmol} / \mathrm{L}$; after $=2.23 \pm 0.23 \mathrm{mmol} / \mathrm{L}$ ) increased after Ramadan. The mean BMI of the study participants (before $=28.30 \pm 6.27$; after $=27.43 \pm 5.92$ ) decreased slightly after Ramadan. The systolic blood pressure (SBP) \pm 7.21 ) showed a slight reduction after Ramadan
\end{abstract}

ONCLSIONS: Type 2 diabetic patients who performed Ramadan fasting displayed a lowering of HbA1c, LDL, TC, and TG, and increased $\mathrm{HDL}$, but had small positive effects on body weight, BMI, as well as SBP and DBP. More studies are needed with a larger population in the future to assess the potential of Ramadan fasting as a therapeutic strategy for managing Type 2 diabetes.

a medical challenge for themselves and their health care providers because Ramadan fasting may influence the glycemic and biochemical parameters [3]. Fasting is associated with increased incidents of hypoglycemia among Type 2 diabetic patients, especially those who are taking hypoglycemic drugs. A recent study by Corley et al. had found that individuals with Type 2 diabetes on hypoglycemic medication are at risk of an increased rate of hypoglycemia episodes [4]. However, other studies have reported that Ramadan fasting is linked with improvement of weight, hemoglobin A1C (HbA1c), and quality of life for diabetic patients [4] Despite the fact that Islam exempts ill Muslims from fasting, many Muslim diabetic patients still choose to fast in Ramadan against the advice of their doctors [5]. 
Stopping taking medications, skipping or reducing the doses, or taking medications at closer intervals without medical supervision increases the risk of complications for adults with Type 2 diabetes [6]. Recent studies have also reported that fasting may be beneficial for diabetes patients and indeed, some have suggested that Type 2 diabetes may be reversible. For example, a study by $\mathrm{Ku}$ et al. reported that fasting participants with Type 2 diabetes did not find any difficulties to the fasting schedule and did not experience any hypoglycemic episodes or other significant adverse effects [7]. The study suggests that fasting can be a viable treatment option for Type 2 diabetic patients [7]. Similarly, a study by Scherger et al. had indicated that remission of Type 2 diabetes can be achieved by lifestyle intervention such as weight loss, cession of antidiabetic medications, and stepped food reintroduction [8]. There are profound changes in dietary habits and lifestyle during Ramadan such as having a large meal after sunset and one lighter meal before dawn that may have an impact on the health of Type 2 diabetic patients [9]. Diabetic Muslim people tend to consume traditional foods which are usually fried and high in carbohydrates so that they put themselves at risk of hyperglycemic, in addition to hypoglycemia during the fasting hours [10]. Several studies in the literature have reported the effects of fasting during the month of Ramadan on blood lipids. Khafaji et al. reported an increase in triglycerides (TG) and a decrease in the level of total cholesterol (TC) [11]. Hadi et al. on the other hand found an increase in the level of cholesterol and no effect on the level of TG [12]. However, some other studies found no change or found only decreased levels of cholesterol during fasting [11], [13]. A recent study by Imam et al. had revealed no changes in TG and TC [14]. This was supported by the findings of a survey in Gaza Strip, which found no significant differences in TC and TG [15]. On the other hand, Kul et al. found a general increase in lipid levels with no change in HDL cholesterol [13]. This finding was in agreement with the result of Elfaki et al., who reported a statistically significant increase in the levels of TC and TG over a month of fasting, with no pathological consequences and with a return to normality after Ramadan ended [14]. Ismail et al. found that the TG level decreased among fasting diabetic patients who adhered to their prescribed diet in the fasting month [16]. The differences between the studies on the effects of Ramadan fasting on the lipid profiles may be due to factors such as changes in diet, use of medications, length of the fasting period, decrease or increase in exercise and physical activities, age, sex, and smoking and possibly genetics [17]. The current study was aimed at investigating the impact of Ramadan fasting on $\mathrm{HbA} 1 \mathrm{c}$, lipid profile, systolic blood pressure (SBP), diastolic blood pressure (DBP), and body mass index (BMI) among Type 2 Saudi diabetic patients in Najran city, Kingdom of Saudi Arabia (KSA). To the best of our knowledge, this is the first study to explore the effects of Ramadan fasting on a group of Type 2 diabetes mellitus patients from Najran city.
Studying different population groups are important to better understand the possible reasons for similarities and differences between the findings of research exploring the impact of Ramadan fasting on Type 2 diabetes patients.

\section{Methodology}

This is a descriptive cross-sectional study exploring the effect of Ramadan fasting on $\mathrm{HbA} 1 \mathrm{c}$, lipid profile, SBP, DBP, and BMI of diabetic people adults and late adolescents attending the outpatient's clinic of Najran University Hospital (NUH) 1 month before and 1 month after the month in Najran KSA.

\section{Participant recruitment and data collection}

The study participants were recruited and selected after receiving responses to distributed posters, from outpatients' clinics at $\mathrm{NUH}$, and by personal contact. The study population comprised all the Saudi persons who were present at 1 day at outpatients' clinics of $\mathrm{NUH}$, including the staff, the patients, and their companions who provided their consent to participate in the study. Study participants comprised adult Type 2 diabetic Muslims who intended to fast during Ramadan and were already diagnosed with diabetes mellitus. Inclusion criteria were defined as being over 18 years old late adolescents and beyond, of Saudi nationality, intending to fast in Ramadan, accepting to participate in the study, living in Najran city, and diagnosed with Type 2 diabetes. Potential participants were excluded from participation in the study if they were very ill, patients with serious complications, non-fasting or refusing to participate in the study, pregnant and lactating ladies, patients with Type 1 diabetes, and those who were below 18 years old, not living in Najran area and the non-Saudi persons. These clinics were chosen because of the higher chance of finding patients who fitted the inclusion criteria of the study. Consent was taken from each participant before filling the questionnaire and giving blood samples. Finally, in this study, the average duration of the fast in the area was approximately $13 \mathrm{~h}$, and the maximum ambient temperature during the summer daytime in Ramadan was $38.9^{\circ} \mathrm{C}$.

\section{Data collection tools}

\section{Questionnaire}

Data were collected by a well-designed questionnaire based on previous similar studies and the investigators' knowledge of the local culture in Najran. A comprehensive medical history was taken by trained medical practitioners in the outpatients' clinics at $\mathrm{NUH}$, where 289 diabetic patients were interviewed. Some other demographic data such as age and gender were recorded 
using a questionnaire designed for this purpose. Qualified nurses also took anthropometric measurements, including body weight $(\mathrm{kg})$ and height in meters $(\mathrm{m})$. Using this information, the BMI was calculated. Height was measured with no shoes worn with the participants elongated to the maximum height and the head positioned in the Frankfort plane using a portable Healthometer (SECA) and was recorded to the nearest $0.1 \mathrm{~cm}$. An electronic weighing scale (SECA) was used to measure weight for the study participants who were not wearing shoes and wearing only light clothing and recorded to the nearest $100 \mathrm{~g}$.

$\mathrm{BMI}$; this study calculated the BMI for the study participants by dividing the weight in kilograms over the square of height in meters [18]. Accordingly, the subjects were categorized according to Quetelet's index as follows:

i. Underweight participants: $\mathrm{BMI}<18.5$.

ii. Normal weight participants: BMI is between 18.5 and 24.9.

iii. Overweight participants: BMI is between 25 and 29.9.

iv. Obese participants: $\mathrm{BMI} \geq 30$.

\section{Physical activity during Ramadan}

For the purpose of this study, we graded physical activity according to the number of episodes of exercise undertaken per week. The patients were categorized as active ( $\geq 3$ times/week) or inactive $(<3$ times/week), according to the recommendations of the American Heart Association [19].

\section{Blood sample collection:}

Participants were requested to attend the central laboratory of NUH on two occasions, between 08.00 and $09.00 \mathrm{am}$, following at least 12-h fast, 1 month before Ramadan (Period 1), 1 month after the end of Ramadan (Period 2). Three samples of $6 \mathrm{ml}$ fasting venous blood were taken to assess glycated hemoglobin $(\mathrm{HbA} 1 \mathrm{c}), \mathrm{TC}$, low-density lipoproteincholesterol (LDL), high-density lipoprotein (HDL)cholesterol, and TG. Blood samples were centrifuged to separate the serum and plasma by centrifuging at 3000 RPM for 5 min and samples were maintained at $-80^{\circ} \mathrm{C}$ until analysis. A fully automated chemical analyzer (COBAS C 311-Analyzer) was used to determine the above parameters and kits used were obtained from Roche Diagnostics $\mathrm{GmbH}$, Mannheim, Germany.

\section{Data analysis}

Data were analyzed using IBM Statistical Package for the Social Sciences (SPSS) version 22.0 (IBM Company, Chicago, USA). Data were checked for normality before analysis. In addition, the statistical comparison of two sets of normally distributed data was performed by an independent t-test to assess the relationship between various variables during Ramadan. A $p<0.05$ was considered to indicate a statistically significant difference.

\section{Results and Discussion}

Type 2 diabetes in Saudi Arabia is known to have one of the highest prevalence of diabetes in the world. According to a report by the International Diabetes Federation (IDF), the prevalence of diabetes in Saudi Arabia is $17.6 \%$ and the number of diabetic people will probably reach seven million by 2040 [20]. This rise in the incidence of diabetes in KSA is due to various factors, such as sedentary lifestyle, obesity, and an aging population [21]. This is the first study from Najran to investigate the impact of Ramadan fasting on Type 2 diabetes patients. There are conflicting results on the impact of Ramadan fasting on type 2 diabetes patients. The current study explored the impact of Ramadan on type 2 diabetes patients from a region of KSA that has not been previously studied.

Table 1: Characteristics of 289 study participants

\begin{tabular}{lll}
\hline Characteristics & Number & Frequency \% \\
\hline Gender & 175 & \\
$\quad$ Male & 114 & $(60.6)$ \\
Female & & $(39.4)$ \\
Age & 116 & \\
18-30 years & 158 & $(40.1)$ \\
$31-50$ years> & 15 & $(54.7)$ \\
50 years & & $(5.2)$ \\
Body mass index (BMI) & 47 & $(16.3)$ \\
$\quad$ Underweight & 81 & $(28.0)$ \\
Normal & 101 & $(34.9)$ \\
Overweight & 60 & $(20.8)$ \\
Obese & $28.30 \pm 6.27$ & \\
$\quad$ Mean of BMI before Ramadan & $27.43 \pm 5.92$ & \\
$\quad$ Mean of BMl after Ramadan & 113 & $(39.1)$ \\
Physical activity during Ramadan & 176 & $(60.9)$ \\
$\quad$ Active & & \\
Inactive & & \\
\hline
\end{tabular}

The study included 289 participants (175 men, 114 women), with a mean age of $42.3 \pm 12.4$. The duration of diabetes in 162 patients was more than 10 years, and the rest were $<10$ years. According to the definitions and categorization of physical activity, our 113 participants fulfilled the criterion of being physically active, and 176 participants fulfilled the criterion of being physically inactive (Table 1). The percentage of glycated hemoglobin $(\mathrm{HbA} 1 \mathrm{c} \%)$ showed a significant decrease in the period after Ramadan $(p<0.05)$ (Table 2). The impact of fasting on $\mathrm{HbA1c}$ for the study participants in relation to gender is

Table 2: Comparison of key parameters before and after Ramadan

\begin{tabular}{llll}
\hline Parameter & Before Ramadan mean \pm SD & After Ramadan mean \pm SD & p-value \\
\hline HbA1c $\%$ & $9.85 \pm 2.37$ & $7.65 \pm 1.70$ & 0.034 \\
LDL mmol/L & $3.39 \pm 1.06$ & $2.40 \pm 0.83$ & 0.032 \\
$\mathrm{HDL} \mathrm{mmol} / \mathrm{L}$ & $1.78 \pm 0.74$ & $2.23 \pm 0.38$ & 0.002 \\
$\mathrm{TC} \mathrm{mmol} / \mathrm{L}$ & $5.98 \pm 2.00$ & $4.05 \pm 1.18$ & 0.023 \\
$\mathrm{TG} \mathrm{mmol} / \mathrm{L}$ & $2.97 \pm 1.95$ & $2.65 \pm 165$ & 0.015 \\
$\mathrm{Mean} \mathrm{BMI}$ & $28.30 \pm 6.27$ & $27.43 \pm 5.92$ & 0.009 \\
Mean SBP & $128.10 \pm 6.32$ & $123.09 \pm 5.71$ & 0.067 \\
Mean DBP & $81.21 \pm 8.51$ & $79.83 \pm 7.21$ & 0.082 \\
\hline " p-value significant at the level of 0.05. & &
\end{tabular}


illustrated in (Figure 1), which indicates that there is no difference in the level of glycemic control between both sexes of the study population. There were significant differences $(p<0.05)$ in the mean concentration of the $\mathrm{LDL}$-cholesterol $\mathrm{mmol} / \mathrm{L}$ in the period before and after Ramadan. The concentration of LDL was higher before Ramadan (3.39 $\pm 1.06 \mathrm{mmol} / \mathrm{L})$ compared to after Ramadan $(2.40 \pm 0.83 \mathrm{mmol} / \mathrm{L})$. Table 2 also shows the effects of Ramadan fasting on the mean concentration of HDL-cholesterol $\mathrm{mmol} / \mathrm{L}$ (before and after Ramadan), a significant difference $(p<0.05)$ was reported. HDL increased after Ramadan (1.23 $\pm 0.38 \mathrm{mmol} / \mathrm{L}$ vs. 2.78 $\pm 1.74 \mathrm{mmol} / \mathrm{L}$ ). In addition, Table 2 displays the effects of Ramadan fasting on the mean concentration of TC $\mathrm{mmol} / \mathrm{L}$, a significant difference was reported $(p<0.05)$. The highest level of TC was seen before Ramadan $(5.98 \pm 2.00 \mathrm{mmol} / \mathrm{L})$, and the lowest was observed after Ramadan $(4.05 \pm 1.18 \mathrm{mmol} / \mathrm{L})$. An analysis of the participants according to their TG $\mathrm{mmol} / \mathrm{L}$ levels showed a significant decrease in the mean concentration of $\mathrm{TG}$ after Ramadan $(p<0.05)$. The concentration of TG was higher before Ramadan $(2.97 \pm 1.95 \mathrm{mmol} / \mathrm{L})$ compared to after Ramadan $(2.65 \pm 1.65 \mathrm{mmol} / \mathrm{L})$. Table 2 also shows the BMI of the study participants. The mean BMI was $28.30 \pm 6.27$ before Ramadan versus $27.43 \pm 5.92$ after Ramadan. On categorizations of BMI, there were $47(16.3 \%)$ underweight, $81(28.0 \%)$ normal weight, 101 (34.9\%) overweight, and 60 (20.8\%) obese. In relation to sex, BMI did not show any significant difference between males and females in the periods before and after Ramadan. Regarding blood pressure, the mean SBP was $128.10 \pm 6.32,123.09 \pm 5.71$ before and after Ramadan did not change significantly ( $p<0.067)$. Likewise, the mean DBP before $(81.21 \pm 8.51)$ and after $(79.83 \pm 7.21)$ Ramadan did not change significantly $(p<0.082)$ (Table 3).

Overall, the findings of the current study indicate improvements in various parameters after the month of Ramada. This includes better glycemic as indicated by $\mathrm{HbA1c}$ levels, which showed significant improvement post-Ramadan. Some studies have shown that there is a significant positive correlation of $\mathrm{HbA1c}$ with lipid profiles suggesting that $\mathrm{HbA1c}$ can

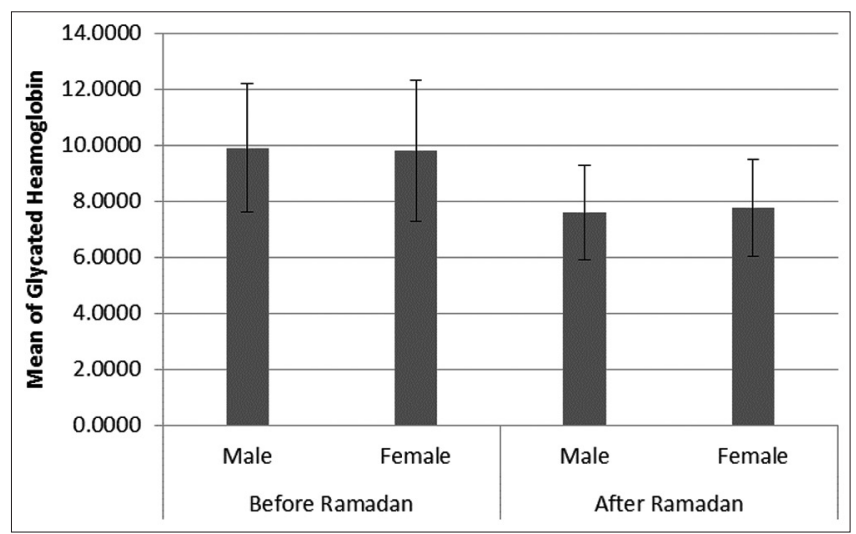

Figure 1: Effect of Ramadan fasting on glycated hemoglobin in relation to gender also be used as a predictor of dyslipidemia, in addition to its role as a glycemic control parameter [22]. Our findings show that there was a $0.22 \%$ reduction of $\mathrm{HbA1c}$ after Ramadan fasting. It has been reported that a $0.1 \%$ reduction of $\mathrm{HbA} 1$ can reduce neurological complications of diabetes by up to 95\% [23] and cardiovascular diseases by $6.8 \%$ [24]. For example, a study by Einhorn et al. reported that patients with fair glycemic control $(\mathrm{HbA} 1 \mathrm{c}<7 \%)$ could significantly decrease the risk of cardiovascular events [25]. The study also had revealed that even a $0.2 \%$ reduction in $\mathrm{HbA} 1 \mathrm{c}$ significantly reduces the risk of mortality by $10 \%$ [25]. The US Department of Health and Human Services states that $0.3 \%$ decrease in $\mathrm{HbA} 1 \mathrm{c}$ is clinically meaningful for diabetic patients' health [26]. It has been reported that lifestyle interventions such as restricted diet and regular physical exercise can lower HBA1c levels resulting in health improvement of people with Type 2 diabetes mellitus [27]. Blood sugar control in patients with diabetes can be achieved through adopting changes in lifestyle such as diet, regular exercise, and anti-diabetic drugs. Some studies have found that better glucose control can be achieved by adjustment of antidiabetic drug dosage in the month of Ramadan [28], [29]. Similarly, a study in Singapore had shown a larger reduction in $\mathrm{HbA} 1 \mathrm{c}$ among diabetic patients who made adjustments to their dose of antidiabetic drugs in Ramadan [30]. A previous study on Turkish patients with Type 2 diabetes before and after Ramadan did not find any negative effects of fasting on the studied group of patients [31]. These findings suggest that Ramadan fasting is unlikely to be risky for well-controlled patients with diabetes. Investigation of effects of fasting on blood glucose in diabetic and non-diabetic persons showed variable results. Some studies evaluated Muslims with diabetes in Ramadan and found that there were no significant changes in patients' glycemic control [32]. An investigation by McEwen et al. found that three-quarters of participants had good glycemic control during Ramadan [33]. A study by Tiboura et al. showed a mild decrease in blood sugar initially in Ramadan, then normalized by the $3^{\text {rd }}$ week of the month with a mild increase by the end of fasting [34]. Some authors have suggested that this influence on the blood glucose level in Ramadan in fasting diabetic patients is unexpected. A study by Alabbood et al. found that there were insignificant glycemic alterations or no change in glycemic control during fasting hours in diabetic persons with baseline $\mathrm{HbA} 1 \mathrm{c}$ below $7 \%$ [35]. Siaw et al. in a study of a group of Muslim people in Singapore found that the significant change noticed during Ramadan was in glycated hemoglobin level; the other parameters showed somewhat milder alterations [22]. The differences between studies reported in the literature could be attributed to many reasons, including lifestyle patterns, different dietary patterns, cultural variations, genetic and geographical locations of study participants and efficacy of the anti-diabetic treatments. Our study 
Table 3: Comparison of blood pressure (before Ramadan) and (after Ramadan) for each BMI† group

\begin{tabular}{|c|c|c|c|c|c|c|c|c|}
\hline Parameters & Underweight & $p$-value & Normal weight & $p$-value & Overweight & $p$-value & Obese & $\mathrm{p}$-value \\
\hline \multicolumn{9}{|l|}{ Systolic BP } \\
\hline Before Ramadan & $130.10 \pm 7.45$ & 0.067 & $119.44 \pm 4.44$ & 0.077 & $122.44 \pm 9.93$ & 0.099 & $118.24 \pm 5.81$ & 0.065 \\
\hline After Ramadan & $127.10 \pm 9.22$ & & $118.60 \pm 11.51$ & & $119.70 \pm 4.95$ & & $122.21 \pm 16.22$ & \\
\hline \multicolumn{9}{|l|}{ Diastolic BP } \\
\hline Before Ramadan & $85.00 \pm 5.65$ & 0.089 & $81.42 \pm 4.96$ & 0.086 & $81.15 \pm 4.03$ & 0.078 & $80.49 \pm 3.83$ & 0.082 \\
\hline After Ramadan & $81.00 \pm 7.07$ & & $74.91 \pm 9.47$ & & $72.38 \pm 18.30$ & & $78.27 \pm 6.03$ & \\
\hline
\end{tabular}

reveals that the Type 2 diabetic patients who performed Ramadan fasting displayed a lowering of LDL, TC, and TG after the month of Ramadan. Furthermore, they showed an increase in HDL. All these changes suggest that Ramadan has positive impacts on the lipid profiles of Type 2 diabetics, although the impact of other factors such medication may also play a role. Similarly, a study conducted by Al-Shafei et al. revealed that an improvement in glycated hemoglobin is associated with a slight decrease in the levels of LDL and TG in Ramadan [36]. However, another study with 114 diabetic patients found changes in $\mathrm{HbA} 1 \mathrm{c}$, LDL, and TG in Ramadan, but not statistically significant [37]. Siaw et al. found clinically non-significant alterations in LDL and TG during the fasting month of Ramadan across three groups of study participants regardless of baseline glycemic control [22].

Our study findings are in line with a previous study, which had found the levels of cholesterol and TG concentrations significantly decreased in fasting people following Ramadan [38]. Moreover, it has been reported that blood cholesterol and TG significantly decrease in the fasting hours in Ramadan compared to pre-Ramadan period [39], [40]. However, a recent study by Khan et al. in Karachi, Pakistan, had found that the effects of Ramadan fasting on TC and TG were not statistically significant [17]. The latter study also found that there was a non-significant rise in the TG and blood sugar value at the end of fasting. Our study had found that TC, LDL, and TG correlate positively with $\mathrm{HbA} 1 \mathrm{c}$ in both periods (before and after Ramadan). In their research, Dionadji et al. had found that there was a small significant increase in TG values in the period after Ramadan, whereas both the HDL and LDL decreased after the month of Ramadan, but these differences were not significant [41]. However, one study reported an increase in LDL and a decrease in HDL [42]. Our study showed an increase in HDL levels compared with pre-Ramadan level of HDL, which agrees with different studies reported for other populations [12], [43], [44]. Overall positive effects of Ramadan on lipid profile in Type 2 diabetic patients have been observed in the current study. Improvement in body lipids may be attributed to physiological changes usually associated with fasting. Smoking cessation or decrease during Ramadan may also have positive effects on lipid profiles.

The body weight and BMI of the study participants did not show significant changes before and after Ramadan. Our study findings are in general agreement with the results of some of the earlier studies. For example, Saada et al. had reported that no statistically significant variations were noted in BMI and weight either during Ramadan or in non-fasting days [45]. However, a recent study by Ramanathan et al. had reported that there is an association between BMI groups and biochemical parameters [46].

In our study, the BMI was not found to be significantly associated with $\mathrm{HbA1c}$ percentage when compared in different BMI groups during the period before and after Ramadan. Similar results were observed in healthy participants in previous studies [47], [48]. Some studies had reported that the normal weight individuals display a weight loss of 1.7-2.0 kg after Ramadan [13]. In contrast, Maislos et al. [49] reported people gain weight during Ramadan for a group of people in KSA. This could be due to physical inactivity which is clearly evident from our study, where $60.9 \%$ of the participants reported being physically inactive. This is in good agreement with a study reported by Alghamdi et al. [50] which used a Fitbit device to monitor individuals with type 2 diabetes from Riyadh in KSA. The latter study reported a high prevalence of low physical activity among Saudi individuals with T2DM. Ramadan during the COVID-19 pandemic was very unusual for many people throughout the world, including those with type 2 diabetes and physical activity may have been further reduced due to lockdowns in some countries [51].

In the current study, we did not observe a statistically significant change in the blood pressure SBP and DBP among the various BMI groups after Ramadan. Importantly, an adverse effect on the blood pressure on Type 2 diabetic patients due to Ramadan was not seen. Since the study populations were attending hospital and were receiving medication, it is possible their blood pressure is relatively well controlled in Ramadan and at other times. However, in the study by Dewanti et al. found that SBP and DBP decreased in Ramadan regardless of fasting diabetic people compliance and attributed this to the decrease in BMI, reflecting a strong link between BMI and both SBP and DBP [52]. While, some studies on the ambulatory checkups of the systolic part of the blood pressure showed that its variations were not marked during Ramadan [36], [53]. This is in agreement with the findings of the current study.

\section{Limitations}

This is the first study for Saudi diabetic patients residing in Najran. The study also includes a significant number of patients and a number of 
different parameters was analyzed. However, the current study has some limitations. First, there was no control group of diabetic patients from Najran who were not fasting, but since the same participants were assessed in two different periods, it was possible to follow and evaluate their progress in relation to glycemic control, lipid profile (self-control), BMI, SBP, and DBP. Second, different types of anti-diabetic drugs used by the study participants and their modifications during Ramadan were not recorded. This could influence their levels of HbA1c since the dose and type of drugs will have different impacts. Finally, we were not able to study the parameters during the month of Ramadan itself and this is to practical reasons since many patients are prepared to give blood during fasting.

\section{Conclusions}

The HBA1c levels and lipid profiles of Type 2 diabetic fasting persons from Najran City in KSA improved after the month Ramadan. This is surprising considering the high level of physical inactivity reported by the study participants. This may be attributed to the well-known benefits of intermittent fasting that have been reported in the literature. Further improvements in the health of diabetics could be attained during Ramadan by increasing physical activity. Overall, the present study adds to the growing evidence that Ramadan fasting may be regarded as not only safe but also beneficial to patients with Type 2 diabetics who are under the guidance of medical practitioners. However, future studies are needed to be conducted with a larger population, including consideration of parameters such as taking or not taking medication and comparing fasting diabetic patients with non-fasting diabetic patients. Ramadan is a month that involves many changes and these should be considered along with fasting to better understand the impact of this month on the health of people.

\section{Acknowledgment}

The authors would like to thank all participants; thanks extend to NUH staff who participated in recruiting participants and in the collection of data. The authors would also like to thank Dr. Gamal Mahamed of Liverpool School of Tropical Medicine for statistical assistance.

\section{Availability of Data and Materials}

The de-identified datasets used and analyzed for the study are available from the corresponding author upon reasonable request.

\section{Authors' Contributions}

P.I.H. \& H.M. designed the research and provided expertise to the project; H.M. conducted the literature reviews and conducted the research; P.I.H. supervised the research. H.M, E.AM.E, S.M.A and A.MB.B performed the data collection and were responsible for the recruitment of study participants. M.A.H. obtained approvals from the NU and participated in the supervision of data collection and critical revision of the article. A.M.A participated in the design of the study, coordination relating to blood sampling and processing. P.I.H, A.M.A and H.M. contributed to the manuscript development and wrote the paper; all authors have read and approved the submitted manuscript for publication. The authors would also like to thank Dr Gamal Mahamed of Liverpool School of Tropical Medicine for statistical assistance

\section{Ethics Approval and Consent to Participate}

Ethical approval to conduct the study was granted by the Ethics Committees of Najran University and De Montfort University Leicester, UK.

\section{References}

1. Kobeissy A, Zantout MS, Azar ST. Suggested insulin regimens for patients with Type 1 Diabetes mellitus who wish to fast during the month of Ramadan. Clin Ther. 2008;30(8):1408-15. https:// doi.org/10.1016/j.clinthera.2008.08.007

PMid:18803984

2. Ibrahim NK, Attia SG, Sallam SA, Fetohy EM, El-sewi F. Physicians' therapeutic practice and compliance of diabetic patients attending rural primary health care units in Alexandria. J Family Community Med. 2010;17(3):121-8. https://doi. org/10.4103/1319-1683.74325

PMid:21359022

3. Bouzid K, Molahedh Y, Hmaidi W, Mchirgui N, Bartkiz A, Talbi $\mathrm{E}$, et al. Effects of Ramadan fasting on clinical and biochemical parameters for Type 2 diabetics. Atherosclerosis. 2016;1:252-93. 
https://doi.org/10.1016/j.atherosclerosis.2016.07.544

4. Corley BT, Carroll RW, Hall RM, Weatherall M, Strong AP, Krebs JD. Intermittent fasting in Type 2 diabetes mellitus and the risk of hypoglycaemia: A randomized controlled trial. Diabet Med. 2018;35(5):588-94. https://doi.org/10.1111/dme.13595 PMid:29405359

5. Alshehri AM. Muslims' Patients' Medication use Behavior and Perceptions Regarding Collaboration with Pharmacists During Ramadan, Doctoral Dissertation; 2018.

6. Almalki MH, Alshahrani F. Options for controlling Type 2 diabetes during Ramadan. Front Endocrinol (Lausanne). 2016;7:32. https://doi.org/10.3389/fendo.2016.00032 PMid:27148163

7. Ku M, Ramos MJ, Fung J. Therapeutic fasting as a potential effective treatment for Type 2 diabetes: A 4-month case study. $J$ Insulin Resist. 2017;2(1):5. https://doi.org/10.4102/jir.v2i1.31

8. Scherger JE. Type 2 diabetes is reversible. Internal Med Alert. 2018;40(5)

9. Al-Arouj M, Assaad-Khalil S, Buse J. Recommendations for management of diabetes during Ramadan: Update 2010. Diabetes Care. 2010;33(8):1895-902. https://doi.org/10.2337/ dc10-0896

PMid:20668157

10. Jaleel MA, Raza SA, Fathima FN, Jaleel BN. Ramadan and diabetes: As-Saum (The fasting). Indian J Endocrinol Metab. 2011;15(4):268-73. https://doi.org/10.4103/2230-8210.85578 PMid:22028997

11. Khafaji HA, Bener A, Osman M, Al Merri A, Al Suwaidi J. The impact of diurnal fasting during Ramadan on the lipid profile, hs-CRP, and serum leptin in stable cardiac patients. Vasc Health Risk Manag. 2012;8(1):7-14. https://doi.org/10.2147/ vhrm.s22894

PMid:22272070

12. Sfar $H$, Sellami $S$, Boukhayatia $F$, Naceur KB, Mami FB. Biochemical, physiological and body composition changes in patients with Type 2 diabetes during Ramadan fasting. IJMBS. 2017;9(6):164. https://doi.org/10.4103/ijmbs.ijmbs_59_17

13. Kul S, Savaş E, Öztürk ZA, Karadağ G. Does Ramadan fasting alter body weight and blood lipids and fasting blood glucose in a healthy population? A meta-analysis. J Relig Health. 2014;53(3):929-42. https://doi.org/10.1007/s10943-013-9687-0 PMid:23423818

14. Imam SA, Alalyani M. Study of effects on physiological parameters due to Ramadan fasting and its impacts on public health. IJIR. 2017;3(3):6-9.

15. El-Taher AM, Zabut BM. Effect of Ramadan fasting on anthropometric measures and some biochemical parameters among Type 2 diabetic patients in Gaza Governorate, Gaza Strip. IUG J Natl Stud. 2015; 21(1):1-16.

16. Ismail S, Shamsuddin K, Latiff KA, Saad HA. Comparing the body mass index, blood pressure and blood biochemical changes during Ramadan between high to moderate level and low level physical activity groups prior to Ramadan among overweight and obese working women. Int J Community Med Public Health. 2016;3(7):1877-83. https://doi.org/10.18203/2394-6040. ijcmph20162059

17. Khan N, Rasheed A, Ahmed H, Aslam F, Kanwal F. Effect of Ramadan fasting on glucose level, lipid profile, $\mathrm{HbA} 1 \mathrm{c}$ and uric acid among medical students in Karachi, Pakistan. East Mediterr Health J. 2017;23(4):274-9. https://doi. org/10.26719/2017.23.4.274

PMid:28634977

18. National Institutes of Health $(\mathrm{NIH})$, National Heart, Lung, and Blood Institute (NHLBI). The Practical Guide: Identification, Evaluation, and Treatment of Overweight and Obesity in Adults. Bethesda: National Institutes of Health; 2000. https://doi. org/10.1037/e310862005-001

19. Centers for Disease Control and Prevention. US Department of Health and Human Services Physical Activity Guidelines for Americans 2008, Washington, DC; 2008.

20. Alshayban D, Joseph R. Health-related quality of life among patients with type 2 diabetes mellitus in Eastern Province, Saudi Arabia: A cross-sectional study. PLoS One. 2020;15(1):e0227573. https://doi.org/10.1371/journal. pone. 0227573

PMid:31923232

21. Kearns K, Dee A, Fitzgerald AP, Doherty E, Perry IJ. Chronic disease burden associated with overweight and obesity in Ireland: The effects of a small BMI reduction at population level. BMC Public Health. 2014;14(1):143. https://doi. org/10.1186/1471-2458-14-143

PMid:24512151

22. Siaw MY, Chew DE, Toh MP, Seah DE, Chua R, Tan J, et al. Metabolic parameters in Type 2 diabetic patients with varying degrees of glycemic control during Ramadan: An observational study. J Diabetes Investig. 2016;7(1):70-5. https://doi. org/10.1111/jdi.12374

PMid:26816603

23. Al-Shoumer K, Al-Asousi A, Doi S, Vasanthy B. Serum leptin and its relationship with metabolic variables in Arabs with Type 2 diabetes mellitus. Ann Saudi Med. 2008;28(5):367-70. https:// doi.org/10.4103/0256-4947.51692 PMid: 18779635

24. Chamnan P, Simmons RK, Forouhi NG, Luben RN, Khaw KT, Wareham $\mathrm{NJ}$, et al. Incidence of Type 2 diabetes using proposed $\mathrm{HbA} 1 \mathrm{c}$ diagnostic criteria in the European prospective investigation of Cancer-Norfolk cohort: Implications for preventive strategies. Diabetes Care. 2011;34(4):950-6. https:// doi.org/10.2337/dc09-2326

PMid:20622160

25. di Angelantonio E, Gao P, Khan H, Butterworth AS, Wormser D, Kaptoge $S$, et al. Glycated hemoglobin measurement and prediction of cardiovascular disease. JAMA. 2014;311(12):1225-33

PMid:24668104

26. Einhorn D, Handelsman Y, Bode BW, Endahl LA, Mersebach $\mathrm{H}$, King $A B$. Patients achieving good glycemic control $(\mathrm{HbA} 1 \mathrm{c}<$ $7 \%$ ) experience a lower rate of hypoglycemia with insulin degludec than with insulin glargine: A meta-analysis of phase $3 \mathrm{~A}$ trials. Endocr Pract. 2015;21(8):917-26. https://doi.org/10.4158/ ep14523.or

PMid:26121451

27. US Department of Health and Human Services, CDER. Guidance for Industry: Diabetes Mellitus: Developing Drugs and Therapeutic Biologics for Treatment and Prevention; 2008. Available from: http://www.fda.gov/downloads/drugs/guidances/ ucm071624.pdf. [Last accessed on 2015 Mar 19].

28. Htoo ZW, Hsu WW, Rosenkranz R. Systematic review and metaanalysis: Is lifestyle modification effective for glycemic control among adults with type II diabetes in Southeast Asia? Diabetes Res Clin Pract. 2016;122:148-53. https://doi.org/10.1016/j. diabres.2016.10.008 PMid:27855340

29. Hassoun AA, Al-Arouj M, Ibrahim M. The effect of vildagliptin relative to sulfonylurea as dual therapy with metformin (or as monotherapy) in Muslim patients with Type 2 diabetes fasting during Ramadan in the Middle East: The VIRTUE study. Curr Med Res Opin. 2017;33(1):161-7. https://doi.org/10.1080/0300 7995.2016.1243093

PMid:27684469

30. Mafauzy M. Repaglinide versus glibenclamide treatment of Type 2 diabetes during Ramadan fasting. Diabetes 
Res Clin Pract. 2002;58(1):45-53. https://doi.org/10.1016/ s0168-8227(02)00104-3

PMid:12161056

31. Bener A, Al-Hamaq AO, Öztürk M, Çatan F, Haris PI, Rajput KU, et al. Effect of Ramadan fasting on glycemic control and other essential variables in diabetic patients. Ann Afr Med. 2018;17(4):196-202. https://doi.org/10.4103/aam.aam_63_1 PMid:30588933

32. Ibrahim M, Al Magd MA, Annabi FA, Assaad-Khalil S, Ba-Essa EM, Fahdil I, et al. Recommendations for management of diabetes during Ramadan: Update 2015. BMJ Open Diabetes Res Care. 2015;3(1):e000108. https://doi.org/10.1136/ bmjdrc-2015-000108

PMid:26113983

33. McEwen LN, Ibrahim M, Ali NM, Assaad-Khalil SH, Tantawi HR, Nasr G, et al. Impact of an individualized Type 2 diabetes education program on clinical outcomes during Ramadan. BMJ Open Diabetes Res Care. 2015;3(1):e000111. https://doi. org/10.1136/bmjdrc-2015-000111

PMid:26113984

34. Tiboura G, Khaled BM, Diaf M, Semeria S, Bouanani G. Effect of Ramadan fasting on serum glucose and lipid profile among Algerian Type 2 diabetes patients. Rom J Diabetes Nutr Metab Dis. 2015;22(4):385-92. https://doi.org/10.1515/ rjdnmd-2015-0045

35. Alabbood MH, Ho KW, Simons MR. The effect of Ramadan fasting on glycaemic control in insulin dependent diabetic patients: A literature review. Diabetes Metab Syndr. 2017;11(1):83-7. https://doi.org/10.1016/j.dsx.2016.06.028 PMid:27402028

36. Al-Shafei Al. Ramadan fasting ameliorates oxidative stress and improves glycemic control and lipid profile in diabetic patients. Eur J Clin Nutr. 2014;53(7):1475-81. https://doi.org/10.1007/ s00394-014-0650-y

PMid:24442382

37. Mikirova N, Hunninghake R, Casciari J, Guilliams V. Effects of micronutrient supplementation on concentrations of vitamins and minerals, inflammation and cardiovascular risk factors. Vitam Miner. 2014;3(120):2. https://doi. org/10.4172/2376-1318.1000120

38. Askari VR, Alavinezhad A, Boskabady MH. The impact of "Ramadan fasting period" on total and differential white blood cells, haematological indices, inflammatory biomarker, respiratory symptoms and pulmonary function tests of healthy and asthmatic patients. Allergol Immunopathol (Madr). 2016;44(4):359-67. https://doi.org/10.1016/j.aller.2015.10.002 PMid:27040808

39. Li Y, Wang DD, Ley SH, Vasanti M, Howard AG, He Y, et al. Time trends of dietary and lifestyle factors and their potential impact on diabetes burden in China. Diabetes Care. 2017;40(12):168594. https://doi.org/10.2337/dc17-0571 PMid:29046327

40. Meo SA, Hassan A. Physiological changes during fasting in Ramadan. J Pak Med Assoc. 2015;65 Suppl 5:S6-14. PMid:26013791

41. Dionadji M, Abdelsalam T, Hisseine A. Metabolic profile of Type 2 diabetic patients before and after Ramadan fasting at an outpatient clinic in N'Djamena. HSD. 2015;16(2):1-4.

42. KMS. Study the effects of Ramadan fasting on the serum glucose and lipid profile among healthy Jordanian students. Am J Appl Sci. 2007;4(8):565-9. https://doi.org/10.3844/ ajassp.2007.565.569

43. Ajabnoor GM, Bahijri S, Shaik NA, Borai A, Alamoudi AA, Al-Aama JY, et al. Ramadan fasting in Saudi Arabia is associated with altered expression of CLOCK, DUSP and IL-1alpha genes, as well as changes in cardio metabolic risk factors. PLoS One. 2017;12(4):e0174342. https://doi.org/10.1371/journal. pone.0174342

PMid:28384165

44. Nematy $M$, Alinezhad-Namaghi, M, Rashed MM, Mozhdehifard, M, Sajjadi SS, Akhlaghi S, et al. Effects of Ramadan fasting on cardiovascular risk factors: A prospective observational study. Nutr J. 2012;11(1):69. https://doi. org/10.1186/1475-2891-11-69

PMid:22963582

45. Saada DA, Selselet G, Belkacemi L, Chabane OA, Italhi M, Bekada AA, et al. Effect of Ramadan fasting on glucose, glycosylated hemoglobin, insulin, lipids and proteinous concentrations in women with non-insulin dependent diabetes mellitus. Afr J Biotechnol. 2010;9(1):87-94.

46. Ramanathan S, Nanda N, Mookkappan S. Effect of body mass index on the association of uric acid and glycemic status in diabetes in South Indian population. Int J Clin Exp Physiol. 2017;4(1):25. https://doi.org/10.4103/ijcep.ijcep_9_17

47. Syam AF, Sobur CS, Abdullah M, Makmun D. Ramadan fasting decreases body fat but not protein mass. Int J Endocrinol Metab. 2016;14(1):e29687. https://doi.org/10.5812/ijem.29687 PMid:27279831

48. Shadman Z, Akhoundan M, Poorsoltan N, Larijani B, Qorbani M, Hedayati $M$, et al. Association of major dietary patterns with cardio-metabolic risk factors in Type 2 diabetic patients. Iran J Public Health. 2016;45(11):1491-501.

PMid:28032067

49. Maislos M, Abou-Rabiah $Y$, Zuili I, lordash S, Shany S. Gorging and plasma HDL-cholesterol-the Ramadan model. Eur J Clin Nutr. 1998;52(2):127-30. https://doi.org/10.1038/ sj.ejcn. 1600526

PMid:9505158

50. Alghamdi AS, Alghamdi KA, Jenkins RO, Alghamdi MN, Haris PI. Impact of Ramadan on physical activity and sleeping patterns in individuals with Type 2 diabetes: The first study using fitbit device. Diabetes Ther. 2020;11(6):1331-46. https://doi. org/10.1007/s13300-020-00825-x

PMid:32367477

51. Elmajnoun $\mathrm{HK}$, Elhag MR, Mohamed $\mathrm{H}$, Haris $\mathrm{PI}, \mathrm{Abu}-$ Median $\mathrm{AB}$. Ramadan 2020 and beyond in the midst of the COVID-19 pandemic: Challenges and scientific evidence for action. Sudan J Med Sci. 2020;15(2):85-110. https://doi.org/10.18502/sjms. v15i5.7147

52. Dewanti L, Watanabe C, Ohtsuka R. Unexpected changes in blood pressure and hematological parameters among fasting and nonfasting workers during Ramadan in Indonesia. Eur J Clin Nutr. 2006;60(7):877-81. https://doi.org/10.1038/ sj.ejcn. 1602393 PMid:16489329

53. Chamsi-Pasha M, Chamsi-Pasha H. The cardiac patient in Ramadan. Avicenna J Med. 2016;6(2):33-8. https://doi. org/10.4103/2231-0770.179547

PMid:27144139 